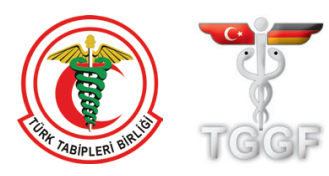

\title{
The effect of nutrient supplementation in the management of polycystic ovary syndrome-associated metabolic dysfunctions: A critical review
}

\author{
(D) Elif Günalan¹, (D) Aylin Yaba², (D) Bayram Yılmaz1 \\ 1Department of Physiology, Yeditepe University School of Medicine, İstanbul, Turkey \\ 2Department of Histology and Embryology, Yeditepe University School of Medicine, İstanbul, Turkey
}

\begin{abstract}
Polycystic ovary syndrome (PCOS) is complex heterogeneous disorder that has several aspects in terms of pathology such as metabolic, endocrine, reproductive, and psychological. However, the etiology of PCOS remains poorly understood. Several studies suggest that insulin resistance and hyperandrogenism play a central role in the progression of PCOS pathophysiology. Therefore, common treatment strategies of PCOS are based on lifestyle modification, which include exercise, diet, and nutrient supplementation therapy. Recent studies have recommended some nutrients such as vitamins, minerals, and vitamin-like nutrients for the therapy of PCOS because each has at least one functional property in PCOS-induced pathways. Therefore, it is claimed that the cause of PCOS could be vitamin or mineral deficiency. This review aims to provide a critical literature survey on nutritional supplementation for the treatment of PCOS-associated endocrine and metabolic dysfunctions and discuss the role of nutrients in the management of PCOS in view of the clinical trials and experimental studies. (J Turk Ger Gynecol Assoc 2018; 19: 220-32) Keywords: Polycystic ovary syndrome, insulin resistance, hyperandrogenism, metabolic dysfunctions, dietary supplements
\end{abstract}

Received: 29 May, 2018 Accepted: 8 October, 2018

\section{Introduction}

The polycystic ovary syndrome (PCOS) is one of the most common endocrine diseases that affects 5 to $10 \%$ of women of adolescent and reproductive age $(1,2)$. PCOS was first defined by Stein and Leventhal in 1935. The basic characteristic trait of PCOS is hyperandrogenism as a result of excessive androgen secretion or activity (3). However, hyperandrogenism is not the only diagnostic criteria for PCOS. According to the Rotterdam criteria, PCOS is defined by the existence of at least two of three criteria, which are hyperandrogenism, chronic anovulation, and polycystic ovaries on ultrasound findings (4). Later, the Androgen Excess and PCOS Society reported that there should be the presence of hyperandrogenism and ovarian dysfunction (anovulation and polycystic ovaries) for PCOS (5). Patients with PCOS have various symptoms including menstrual dysfunction, hyperinsulinemia, infertility, glucose intolerance, type 2 diabetes, hirsutism, obesity, acne, metabolic syndrome, increased risk for the development of cardiovascular diseases, endometrium cancer, anxiety, obstructive sleep apnea, and abnormalities of lipid profile $(6,7)$.

Although there are extensive studies in the literature, the cause of PCOS remains unclear due to poorly understood interactions between genetic and environmental factors (8). Reproductive neuroendocrine defects, impaired ovarian steroidogenesis, insulin resistance (IR), and increased cortisol metabolismrelated adrenal hyperandrogenism can be among the causes of PCOS (9-11). Recent studies suggest that IR contributes to both metabolic and reproductive disturbances. Therefore, IR has a central role in the pathogenesis of PCOS (12). Briefly, insulin is considered as a key hormone for hyperandrogenism in the PCOS pathophysiology via two different pathways: 1) 
insulin stimulates androgen production of theca cells with luteinizing hormone (LH) and elevated androgen production leads to hirsutism, acne, and anovulatory infertility. 2) Hyperandrogenism associated function of insulin is inhibition of sex hormone-binding globulin (SHBG) synthesis in the liver (13). SHBG is a plasma protein for androgen and estrogens and so decreased SHBG levels can lead to hyperandrogenism in PCOS. At the metabolic perspective, insulin plays a key role in regulating glucose metabolism, blocking of lipolysis, and activation of aminoacid transportation (14). Various nutrients have regulatory roles in the insulin signaling pathway and androgen synthesis.

Providing sufficient nutrients and energy for growth and reproduction depend on the definition of the optimal nutrient composition. It is clear that nutrition-associated signaling pathways play a central role in the regulation of ovarian follicle growth and ovulation rates (15). In particular, deficiencies of myo-inositol and vitamin D can lead to PCOS pathogenesisrelated complications (16-18). Therefore, nutritional supplementation may contribute to overcome complications of PCOS such as immature oocyte, IR, hyperandrogenism, and oxidative stress. This review addresses current knowledge about the efficacy of nutrients in the treatment of PCOS in view of experimental studies and clinical studies.

\section{Vitamin Supplements}

Vitamin $\mathbf{A}$ is a fat soluble vitamin also known as retinol. Vitamin A-derived metabolites such as retinoids, retinoic acid, and retinol contribute to antioxidant activity, steroid metabolism, oocyte nuclear maturation, and inhibition of cumulus cell apoptosis $(19,20)$. It is known that retinoic acid synthesisrelated genes are expressed differentially in theca interna cells isolated from patients with PCOS (21). To examine the effects of retinol and retinoids, derivatives of retinol were applied into theca interna cell culture obtained from PCOS and healthy women. All trans retinol-treated theca interna cells gave rise to increased dehydroepiandestrone levels and mRNA accumulation of cytochrome P450 $17 \alpha$ hydrxylase (CYP17) involved in androgen production and retinol biosynthesis (22). Obesity and abnormal glucose metabolism are associated with elevated retinol-binding protein 4 (RBP4) levels in overweight women with PCOS (23). Another RBP4-based study reported the measurement of RBP4 expression in isolated subcutenous and omental adipose tissue from women with PCOS. The authors suggested that elevated $17 \beta$ estrodiol could contribute to the altered gonadal and adrenal steroid profile via upregulation of the RBP4 gene (24).

B group vitamins; most studies focus on B6, B12, and folic acid in this group due to the increasing role of homocysteine (Hcy) in PCOS. In this mechanism, Hcy is an essential amino acid derived from dietary methionine and elevated total plasma Hcy levels lead to an increased risk for cardiovascular and reproductive symptoms in PCOS (25). In addition, other metabolic pathways required for growth of cell and tissue are closely associated with Hcy (26). Folic acid, vitamin B6, and vitamin B12 have significant roles in Hcy regulation. In the physiopathology of PCOS, a positive correlation has been reported between IR and elevated Hcy levels $(27,28)$. Kaya et al. (29) demonstrated that IR, obesity, and increased Hcy levels were related to low serum insulin B12 concentrations in women with PCOS. In order to reduce elevated levels of serum Hcy, folic acid supplementation for three months produced effective results, especially in women without IR. However, a dose-dependent effect of folic acid supplementation is not known (30). Regular exercise has also been suggested to decrease plasma Hcy concentrations in the pathophysiology of PCOS. According to the study of Randeva et al. (31) regular exercise for a period of six months provides significantly lower plasma Hcy levels in young obese and overweight women with PCOS.

Many women with PCOS have to use insulin-sensitizing agents such as metformin for improving insulin sensitivity. Metformin inhibits the binding intrinsic factor- $\mathrm{B}_{12}$ complex and its receptor, and also serum vitamin B12 and folic acid levels decrease during metformin therapy (32). In addition, metformin increases Hcy levels; therefore it gives rise to the long-term risk of cardiovascular diseases in women with PCOS (33). The interaction between metformin and B group vitamins has been explained by two studies: the first report showed that daily administration of folic acid or B group vitamins could be effective in reducing elevated Hcy levels in women with PCOS in short-term metformin therapy. However, the authors also suggested that supplements of vitamins had no effects on androgen and lipid levels in the pathophysiology of PCOS (34). The second report showed that the use of metformin with folate supplementation for six months had beneficial effects on vascular endothelium. This treatment provides reduced Hcy levels, thus it can be effective in the management of the longterm complications of PCOS such as cardiovascular disorders (35)

Inositol and its metabolites are known as sugar alcohols and also belong to B complex vitamins. In addition, inositol has 9 stereoisomers such as myo-, cis-, allo-, epi-, muco-, neo-, scyllo-, D-chiro and L-chiro- forms (36). Inositol-derived metabolites have essential roles in insulin sensitivity as second messengers, lipid synthesis, signal transduction, oocyte maturation, oogenesis, cell morphogenesis, and cytoskeleton organization (37). According to randomized controlled studies involving inositol supplementation in women with PCOS, inositol provides improvement in almost all pathologic conditions 
in PCOS such as recovery of reproductive abnormalities, decreased androgen levels, and improved insulin levels (38). Interestingly, combined treatment of inositol isomers such as myo-inositol (MI) and D-chiro inositol (DCI) should be applied at a certain ratio, which is known as the plasma physiologic ratio (MI/DCI: 40/1) (39). Otherwise, immature oocytes can appear, and the efficacy of inositol is decreased in the pathophysiology of PCOS (40). Some studies have claimed that these pathologic conditions may be accounted for by the 'DCI paradox' (41). Briefly, MI is found in the follicle-stimulating hormone (FSH) signaling mechanism and homeostasis of glucose uptake, and DCI is prompted to insulin-associated androgen synthesis. Epimerase plays a functional role in conversion of MI to CDI depending on insulin levels and also intake of inositol isomerase, except the physiologic ratio can lead to decreased MI and increased CDI levels. When hyperinsulinemia occurs in the pathogenesis of PCOS, elevated epimerase activity can lead to abnormalities in the FSH signaling pathway; therefore, immature oocytes and hyperandrogenism may develop (42). Contributions of MI to treatment in women with PCOS are reviewed in Table 1 (43-50). According to the current literature, treatment of MI provides healing in hyperandrogenism and IR- associated parameters, and also improvement of the lipid profile.

Vitamin D is so essential vitamin for skeletal growth, regulation of serotonin synthesis, bone mineral density, dental health, lower extremity functions, and regulation of calcium $(\mathrm{Ca})$ and phosphorus metabolism. In addition, previous studies reported

Table 1. Effects of myo-inositol compounds in women with PCOS

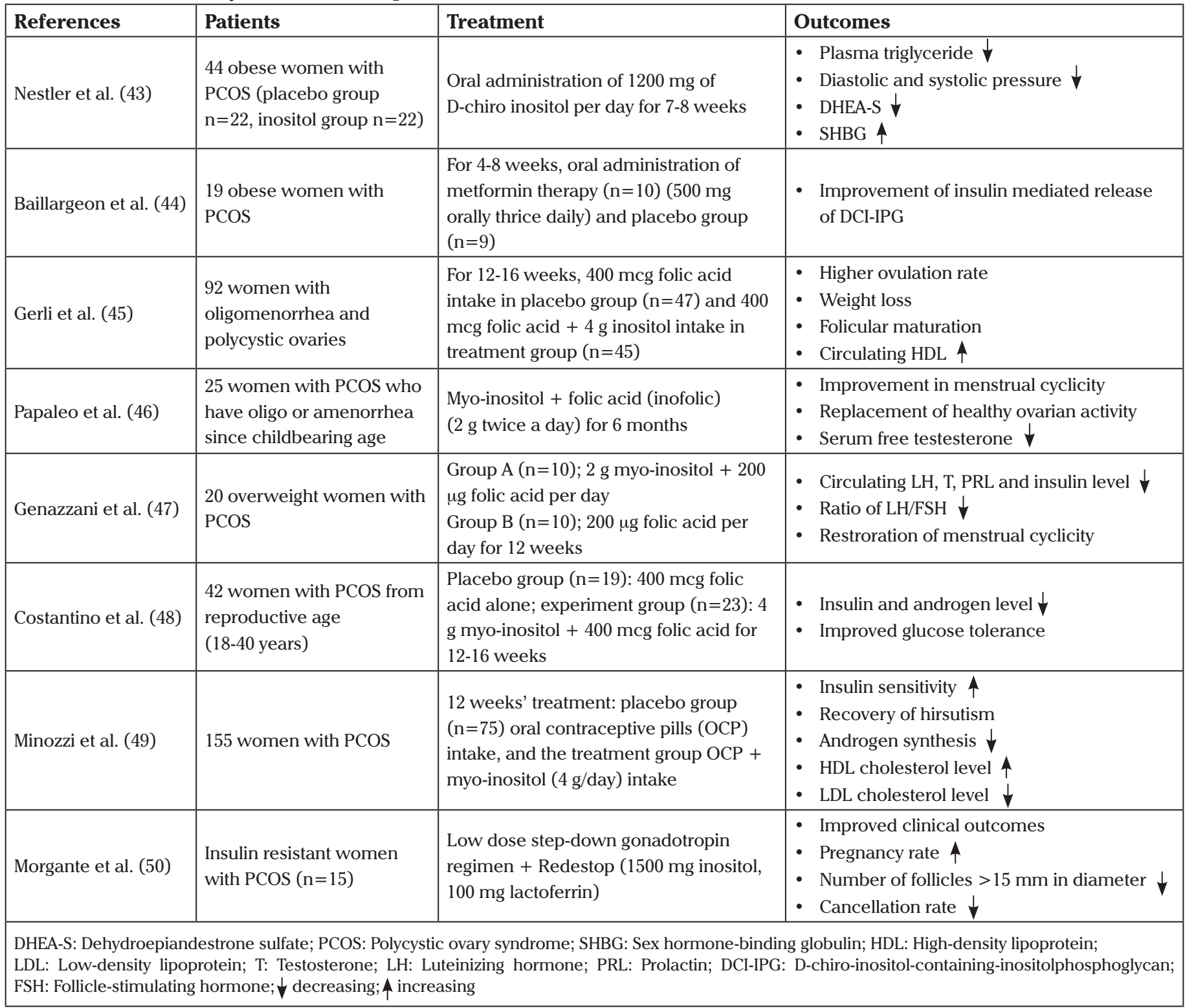


that vitamin D might be a significant and independent predictor of IR (51). Vitamin D levels decrease in obese patients when compared with non-obese people owing to IR. Regarding to PCOS, a recently published review by Krul-Poel et al. (52) about the role of vitamin D in metabolic disturbances of PCOS confirmed an association between vitamin D and metabolic disturbances. Thereby, it was found that women with PCOS (who are obese) had significantly decreased 25-dehydroxy vitamin D levels (53). Moreover, a cross-sectional study reported that lower $\mathrm{D}$ vitamin was linked with $\mathrm{IR}$ as a result of the pathophysiology of PCOS (54).

Researchers focus on vitamin D supplementation for the treatment of women with PCOS to show an interaction between vitamin D deficiency and PCOS. A recent study about vitamin $\mathrm{D}$ replacement therapy in which vitamin D3 was administered for three weeks in 11 subjects with PCOS suggested some beneficial effects on IR, but no changes in androgen levels were observed (55). In addition, Kotsa et al. (56) used a vitamin D3 analogue (alphacalcidol) in order to determine the effect of vitamin D in the treatment of PCOS. Their findings showed an increased first phase of insulin secretion, decreased serum triglyceride (TG) levels, and increased serum high-density lipoprotein (HDL) cholesterol profile.

The molecular mechanism between vitamin $\mathrm{D}$ supplementation and improvement of PCOS is currently unknown. However, a recent report claimed that vitamin D3 replacement treatment in women with PCOS improved some biochemical parameters by increasing in amount of soluble receptor for Advanced Glycosylated Ends (AGEs). Therefore, vitamin D3 inhibits inflammatory progress in the pathogenesis of PCOS. Moreover, vitamin D3 treatment plays a vital role in folliculogenesis due to decreasing elevated anti-mullerian hormone levels (57). Interestingly, Jafari-Sfidvajani et al. (58) demonstrated that vitamin D supplementation in women with PCOS caused no statistically significant differences in the androgen profile when combined with a low-calorie diet; however, an improvement in menstrual frequency was observed.

Vitamin E is a lipid-soluble vitamin and free radical scavenger that regulates the balance between antioxidant and oxidant systems (59). In addition, new evidence confirmed that vitamin $\mathrm{E}$ could improve endometrial thickness in women with unexplained infertility, and the effects were attributed to its anticoagulant and antioxidant effects (60). Moreover, cotreatment of coenzyme q10 and vitamin E for 8 weeks in patients with PCOS provided improvement in SHBG concentrations (61). Another study showed that vitamin E (400 IU) and omega-3 fatty acid (1000 mg) co-supplementation in women with PCOS for 12 weeks provided significant improvement in IR and androgen levels (62).

\section{Supplementation of Vitamin-like Nutrients in PCOS}

Alpha-Lipoic Acid (a-LA) is a free radical scavenger, an essential cofactor in the citric acid cycle, and a regulatory agent of body weight $(63,64)$. Interestingly, Masharani et al. (65) found that controlled release of $\alpha$-LA administered to six nondiabetic women with PCOS was not related with elevation in plasma antioxidant potency or reduction in plasma oxidation metabolites. To investigate the role of $\alpha$-LA and DCI (DCA) in the short-term management of PCOS, both metabolites were given to 46 women (26 women with PCOS and 20 female controls) for 180 days. They suggested that some reproductive characteristics improved including menstrual cycles, decreased number of ovarian cysts, and increased progesterone levels. At the metabolic perspective, IR significantly improved in the subjects wiht PCOS, and impaired lipid metabolism was significantly changed (66).

Bioflavonoids consist of polyphenolic compounds, which are found in plants. Flavonoids have antioxidant, antidiabetic, antiestrogenic, anti-inflammatory, and antiproliferative properties (67). Bioflavonoids consist of various metabolites, some of which provide improvement of the pathogenesis of PCOS at different levels. For instance, Oh et al. (68) analyzed six flavonoid classes (anthacyanides, flovan-3-oils, flavanones, flavones, flavonols and isoflavones) in terms of their contribution to the treatment of metabolic syndrome in PCOS pathophysiology. The authors suggested that only flavonol consumption was the most effective treatment of metabolic syndrome in PCOS when compared with the other groups (68). Romualdi et al. (69) showed that $36 \mathrm{mg} / \mathrm{d}$ soy isoflavone genistein treatment in women with PCOS for three months provided a significantly improved lipid profile. However, other characteristic traits of PCOS such as hyperinsulinemia, anthropometric measurements, hyperandrogenism, and reproductive abnormalities did not change significantly (69). On the contrary, in an experimental study on rats, Shah and Patel (70) reported improved ovarian and uterine morphologic appearences, increased LH levels, and significantly decreased insulin and testesterone in PCOS following quercetin treatment, a bioflavonoid with antioxidant activity. They considered that quarcetin was functional in phosphatidylinositole-3-kinase (PI3K) inhibition and therefore PI3K could be beneficial target for a novel therapy approach of PCOS (70).

Carnitine is a quaternary ammonium compound found in fatty acid metabolism, oxidative stress mechanisms, and glucose metabolism (71). According to a clinical study, nonobese women with PCOS have significantly decreased serum total L-carnitine levels when compared with healthy women (72). Fenkci et al. (72) considered that lower L-carnitine level could be linked with hyperandrogenism and IR. Consistently, 
some antidiabetic agents that are used for PCOS treatment are associated with carnitine metabolism. For instance, piaglitazone administration for 16 weeks in obese premenoupausal patients with PCOS led to increased fasting concentrations of free carnitine (73). Moreover, Dunning and Robker (74) claimed that L-carnitine influenced oocyte quality because L-carnitine provides transport of fatty acids and regulation of energy production, which have a central role in promoting oocyte maturation. Immature oocytes can be a source of metabolic and endocrine malfunctions in PCOS (75). A randomized clinical trial in clomiphene-resistant women with PCOS reported that using both clomiphene citrate and L-carnitine provided thicker endometrium, higher estradiol concentrations, higher pregnancy rates, and improved lipid profiles compared with clomiphene citrate treatment alone (76). Another study demonstrated that L-carnitin supplementation (250 mg per day) for 12 weeks had beneficial effects within mental health and oxidative stress parameters (77).

\section{Mineral Supplements}

Mineral supplements are among the dietary supplements that are expexted to provide improvement of metabolic profile, mental health, ovulation, and menstrual cyclicity. Recent studies about PCOS focused on mineral supplementation in order to remove pathologic situations from PCOS.

Calcium is an essential micronutrient and is involved in egg activity, oocyte maturation, progression of follicular development, and regulation of cell division in mammalian oocytes (78-80). Furthermore, Ca deficiency could be related to risk of obesity because the insulin signaling pathway is $\mathrm{Ca}$ dependent (81). Therefore, it is considered that abnormalities of $\mathrm{Ca}$ concentrations could be associated with IR and promoting PCOS pathologies. Biochemical studies have shown that decreased $\mathrm{Ca}$ levels are observed in obese women with PCOS when compared with healthy women. Ca homeostasis depends on vitamin D receptor (VDR), parathyroid hormone (PTH), and Ca-sensing receptor (CaSR). In addition, adiponectin concentration is strongly associated with $\mathrm{Ca}$ and vitamin $\mathrm{D}$ levels (82). To determine the role of the polymorphisms of $\mathrm{Ca}$ homeostasis-linked factors in initiating PCOS, VDR, PTH, CaSR insulin receptor, and adiponectin genes were analyzed and compared with PCOS-associated biochemical parameters. Consequently, polymorphisms of VDR are related to increased $\mathrm{LH}$ and reduced SHBG levels and the gene variant of CaSR is linked to higher homeostatic model assessment-IR (HOMAIR) and IR (83). Combined supplementation of vitamin D 100,000 IU/month, Ca $1000 \mathrm{mg} /$ day, and metformin $1500 \mathrm{mg} /$ day for 6 months in 100 infertile patients with PCOS resulted in significanly reduced body mass index (BMI). In addition, menstrual cyclicity, follicular maturation, and pregnancy rates were affected positively, but the alterations were not statistically significant (84).

Chromium is an essential mineral that has an essential role in carbohydrate and lipid metabolism. Chromium has been widely studied in the treatment of hyperglycemia, especially type 2 diabetes, because chromium deficiency leads to disorders in glucose homeostasis and IR (85). There is also evidence to confirm that women with PCOS showed decreased chromium levels, which was linked to IR (86). A pilot study suggested that with daily supplementation of $200 \mu \mathrm{g}$ chromium for three months, women with PCOS showed improved glucose tolerance, but it did not affect reproductive function and hormonal disturbances (87). Another study involving 64 women with PCOS showed that daily $200 \mu \mathrm{g}$ chromium supplementation for eight weeks caused significant decreases in serum insulin levels, HOMA-IR, HOMA-B, TGs, very-low-density lipoprotein (VLDL) cholesterol, and total cholesterol concentration. In addition, Jamilian and Asemi (88) showed that a significantly increased quantitative insulin sensitivity check index (QUICKI) score in women with PCOS compared with placebo. However, circulating LDL, HDL, cholesterol levels, and fasting plasma glucose levels were not altered in the treatment group (88).

The effect of chromium within androgen level depends on the treatment amount and duration of chromium treatment. According to a double-blind, randomized clinical study, chromium picolinate $(200 \mu \mathrm{g} /$ day $)$ treatment in 46 patients with clomiphene citrate-resistant PCOS for 3 months gave rise to increased insulin sensitivity. However, there were no findings about a relationship between applied chromium and androgen levels (89).

In contrast, Amr and Abdel-Rahim (90) administered high doses of chromium picolinate $(1000 \mu \mathrm{g} /$ day $)$ treatment to adolescent girls with PCOS for 6 months. At the end of the study, improvement of oligo/amenorrhea, decreased number of total follicles, lower free testesterone levels, and smaller ovarian volume were obtained in ultrasonographic views and biochemical analyses.

Magnesium is the one of the most predominant intracellular cations (91). Magnesium regulates ATP-generation, ATP-use, transphosphorylation reactions, DNA and RNA synthesis, insulin metabolism, ion homeostasis, membrane structure, cytoskeletal function, and cell growth (92). In addition, magnesium is associated with entry of $\mathrm{Ca}$ into the neuron because magnesium is a $\mathrm{Ca}$ antogonist and a voltagedependent blocker of the N-methyl-D-aspartate channel $(93,94)$. This property provides protection for neurons against cell death. Therefore, magnesium supplementation is used generally in neurologic disorders including depression-related diseases such as PCOS, as well hypertension, cardiovascular diseases, and diabetes $(95,96)$. However, only a few studies 
have suggested a relationship between serum magnesium level and the pathogenesis of PCOS. Lower serum magnesium level and higher $\mathrm{Ca} / \mathrm{Mg}$ ratios in women with PCOS due to IR have been reported. No significant correlation between $\mathrm{Mg}$ levels and steroid hormones was found (97). The effects of magnesium levels in PCOS pathology remains unclear.

Selenium is an effective essential element against oxidative stress and is required for the embryonic gonodal development and function of reproductive tissues (98). Biochemical studies have shown that women with PCOS have lower selenium level compared with controls. Coskun et al. (99) suggested that accumulation of free radicals was detected in PCOS women due to insufficient selenium level, which leads to increased androgen levels including LH and total testesterone (99). In this regard, selenium supplementation in the form of immunomodulatory drug (IMOD) was administered for 21 days to hyperandrogenism-induced PCOS female rats. IMOD reduced tumor necrosis factor- $\alpha$ production and increased antioxidant capacity (100).

Another aspect of selenium intake is related to glucose and fat metabolism because selenium possesses insulin-like activities $(101,102)$. There were two clinical studies about the effect of selenium supplementation in women with PCOS in terms of IR. In the first study, 70 women with PCOS were randomly divided into two groups, one received $200 \mu \mathrm{g}$ per day selenium supplements $(n=35)$ and the other placebo $(n=35)$. After 8 weeks of intervention, they reported a reduction in serum insulin levels, HOMA-IR, HOMA-B, and increased QUICKI. Also, selenium intake showed decreased serum TGs and VLDL-C concentrations when compared with placebo (103). Another study included $200 \mu$ g selenium supplementation $(n=20)$ and placebo $(n=20)$ per day for 8 weeks in 40 infertile women with PCOS. At the end of the study, the authors measured the insulin and lipid-related gene expression levels such as PPAR- $\gamma$, GLUT1 , and LDLR from lymphocytes in the subjects. The results showed that selenium supplementation could be a candidate for in vitro fertilization due to significantly increased expression levels of PPAR- $\gamma$ and GLUT-1 and decreased expression levels of LDLR (102).

Zinc is an another essential trace element found in the metabolism of lipid, carbohydrates, and protein, which is responsible for the function of over 300 enzymes. It is a component of more than 200 enzymes (104). In particular, zinc ions play crucial roles in insulin metabolism including the synthesis, storage, secretion, conformational integrity, function, and action of insulin, and also zinc ions produce an insulin-like effect (105). For this reason, insufficiency of zinc gives rise to diabetes, obesity, glucose intolerance, lipidemia, hyperglycemia, and hypertriglyceridemia (106,107). Studies have shown that women with PCOS have lower zinc levels
(108). It has been demonstrated that one of the reasons for IR in PCOS was related to decreased insulin-dependent tyrosine phosphorylation due to a post-receptor defect $(109,110)$. Therefore, inadequate zinc levels could not stimulate insulin receptor tyrosine kinase in patients with PCOS. Zinc levels can play an important role in the development of IR in PCOS. Several studies suggested that zinc supplementation had therapeutic effects for the prevention of type 2 diabetes (111).

The pathology of PCOS involves risk of cardiovascular diseases in the long term due to altered lipid profiles including elevated trygliceride levels, decreased HDL levels, and increased LDL levels (112). It has been suggested that zinc deficiency in PCOS might be associated with abnormal lipid profiles. The effect of zinc supplementation in women with PCOS has been shown in recent clinical research (113). In this study, $50 \mathrm{mg} / \mathrm{d}$ of zinc as zinc sulphate or placebo was given to 60 women with PCOS for 8 weeks, as an adjunct to their pre-study oral estrogenprogestrone compound therapy. The results showed a significant reduction in levels of serum total cholesterol, LDL-C, $\mathrm{TG}$, and TG/HDL-C ratio in the zinc group (113). Therefore, zinc supplementation can provide an effective adjunctive nutritional therapy with potential for improving lipid metabolism and IR in women with PCOS.

\section{Other Supplements}

Melatonin (MT) is a neuroendocrine hormone secreted from the pineal gland. It plays a central role in the regulation of circadian rhythm. High concentrations of MT have been found in follicular fluid, which affects physiologic processes in the ovaries such as folliculogenesis, follicular atresia, ovulation, steroidogenesis in theca cells, and corpus luteum formation due to its powerful free radical scavenger activity (114-116). Moreover, Wei et al. (117) reported that supplementation of MT at a low concentration supports nuclear maturation of oocytes in vitro. Therefore, MT may provide improvement of oocyte quality and increase pregnancy rates (118). Concentration of MT in pre-ovulatory follicular fluid is lower in women with PCOS. Kim et al. (119) suggested that MT administration may be useful in in vitro fertilization strategy and improve clinical outcomes of PCOS

$\mathbf{N}$-acetyl-L-cysteine (NAC) is the acylated form of L-cysteine amino acid and also one of the precursors of glutathione, an antioxidant substance (120). Liu et al. (121) showed that NAC administration supported oocyte quality through an antiaging effect on mouse oocytes. In addition, NAC regulates insulin receptor function in eryhtrocytes and supports insulin secretion from the pancreatic $\beta$ cells (122). Fulghesu et al. (123) investigated the effects of NAC administration for 5-6 weeks on insulin-associated parameters in obese and lean women. They determined a significant decrease in testesterone and androgen levels. In addition, increased 
peripheral insulin sensitivity appeared in women with PCOS (123). Thus, both metformin and NAC have important effects on hyperandrogenism, hyperinsulinemia, and menstrual cyclicity in women with PCOS. Elnashar et al. (124) compared the effects of metformin and NAC on insulin and testesterone levels and ovulation success in women with clomiphene citrate-resistant PCOS. In fact, clomiphene citrate is used in the first-line treatment of PCOS as a stimulator of ovulation. However, resistance against clomiphene citrate in women with PCOS obstructs the possibility of pregnancy. As a consequence, it was suggested that metformin had more efficacy in ovulation rates $(51.6 \%)$ and insulin sensitivity than NAC (124). Another clinical trial compared metformin use (500 mg three times daily) and NAC supplementation (600 mg three times daily) over a 24-week period. Both groups had equal efficacy in terms of decreased BMI and free testesterone levels, improved insulin sensitivity, menstrual cyclicity, and lower hirsutism scores. Moreover, metformin administration caused a decrease in total cholesterol levels and NAC supplementation led to reduction in both total cholesterol and LDL levels (125).

Omega 3 Fatty Acids are polyunsaturated fatty acids (PUFAs). $\alpha$-linolenic acid, eicosapentaenoic acid (EPA), and docosahexaenoic acid (DHA) are the most commnly known members in this group. Each fatty acid has distinct metabolic and endocrine properties and PUFAs intake can be linked to reduced TG, whereas monounsaturated fatty acids (MUFAs) consumption leads to decreased testesterone level (126). Omega-3 fatty acids reduce oxidative stress, decrease hypertension, and improve lipid profiles and anti-inflamatory activity, and so they have potential role against cardiovascular disease risk $(127,128)$. In recent years, omega-3 fatty acids have been considered as therapeutical agents for the treatment of PCOS. It has considered that the healing mechanism of omega-3 is associated with regulation of abnormal gene expression in the pathophysiology of PCOS. For instance, different doses (25-100 $\mu \mathrm{g})$ of omega-3 EPA in granulosa cell culture resulted with higher insulin growth factor (IGF)-1 expression and lower cycloxogenase 2 (COX2) expression. It is clear that IGF-1 is an essential compound of follicular differentiation and COX-2 contributes to oocyte maturation (129).

The relationship between IR and omega-3 supplementation has been discussed by various researchers due to inconsistent findings. However, a meta-analysis about the effects of omega-3 in the IR-associated pathology of PCOS reported no association between intake of omega-3 and insulin sensitivity (130). Some clinical studies are briefly summarized in Table 2 (131-136).

Table 2. According to clinical studies, the role of omega-3 in the treatment of PCOS

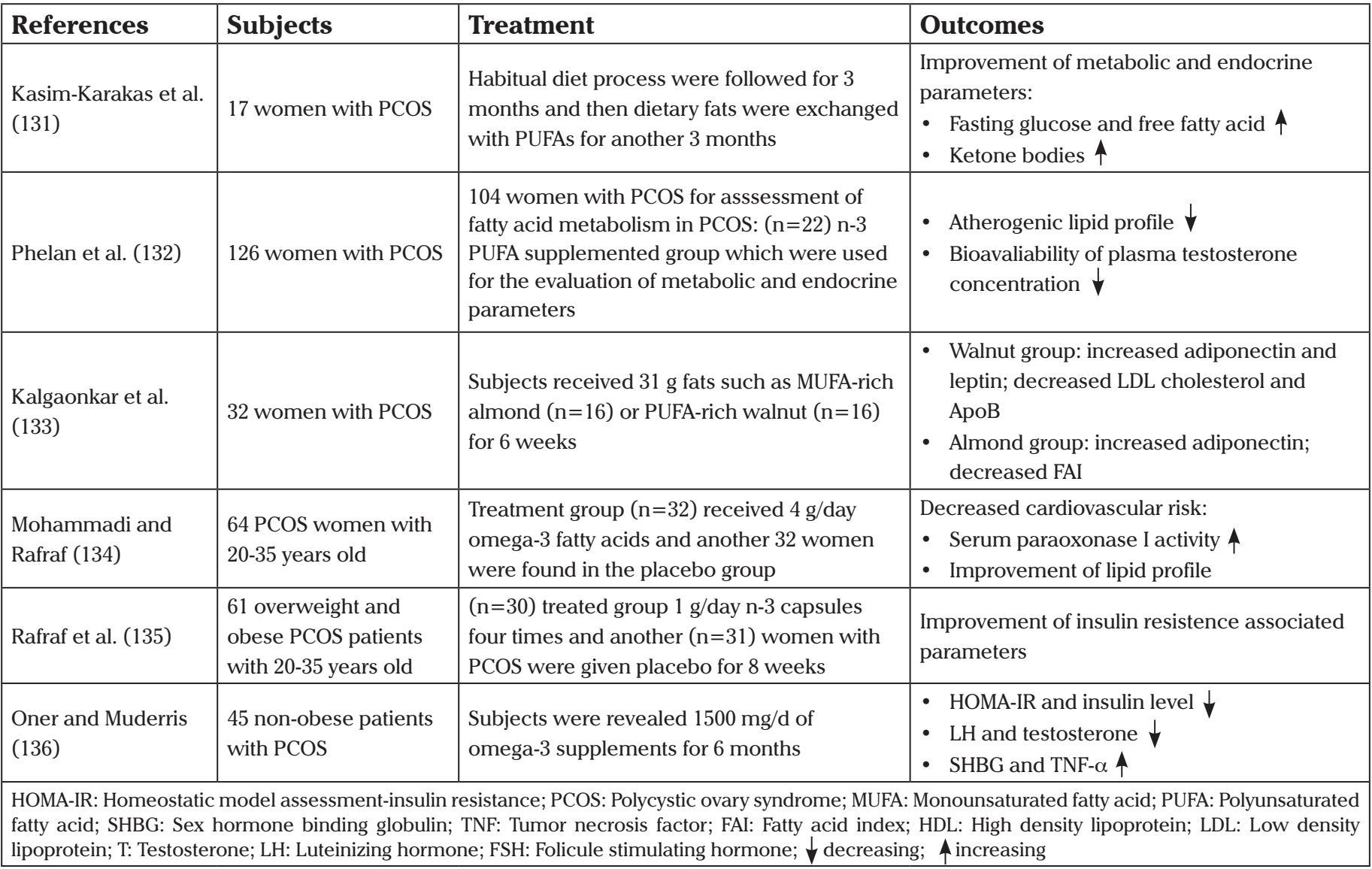


Probiotics are living microbial dietary supplements found in dairy products and have synergism with the gut microbiota (137). Probiotics have beneficial effects in metabolism, especially under inflammatory conditions $(138,139)$. According to recent studies, probiotic consumption improves fasting blood glucose and antioxidant status in patients with type 2 diabetes (140). In addition, Yadav et al. (141) showed that a probioticsupplemented diet delayed the onset of glucose intolerence, hyperglycemia, hyperinsulinemia, and dyslipidemia in diabetic rats. Shoaei et al. (142) studied the effects of probiotic supplementation on pancreatic $\beta$ cells and C-reactive protein (CRP) in patients with PCOS using multispecies probiotics for 8 weeks. The results of their study showed reduced fasting blood sugar and serum insulin levels in a crude model. Interestingly, CRP levels did not significantly change.

The etiology of PCOS has two pathologic conditions including a chronic state of inflammation and IR (143). Both conditions are associated with the dysbiosis of gut microbiota (DOGMA) theory. The background of DOGMA involves an imbalance in gut microbiota, i.e., increasing the transition of Gram-negative colonic bacteria into the systemic circulation. Therefore, a chronic inflammatory response occurs in the host. The inflammatory process affects insulin receptor function and PCOS-associated pathways such as androgen biosynthesis.
Therefore, to overcome the pathophysiologic conditions of PCOS, probiotic supplements are recommended by some researchers $(144,145)$. On this point, Guo et al. (146) performed fecal microbiota transplantation (FMT) and lactobacillus transplantation in rats with PCOS. At the end of the study, they reported that all rats in the FMT group had an improved estrous cycle and most of the lactobacillus-treated rats had decreased androgen biosynthesis (146).

The pathophysiology of PCOS is associated with various defects, including neuroendocrine defects, impaired ovarian steroidogenesis, IR, and increased cortisol metabolism-related adrenal hyperandrogenism. Although the triggering cause of PCOS is currently unknown, androgens and insulin are thought to be two key factors in its pathogenesis. Therefore, treatment of PCOS is required to overcome both hyperandrogenism and hyperinsulinemia. Nutrients act as cofactors in maintaining functions of insulin and androgen receptors. In this study, we focused on the efficacy of nutrient supplementation in management of PCOS because almost all vitamin and mineral deficiencies are seen in PCOS. In this process, published clinical and experimental studies that met specified criteria were extracted from PubMed, Web of Science, EmBASE, Google Scholar database from the last 25 years as accurately and precisely as possible. Articles were divided into treated nutrient

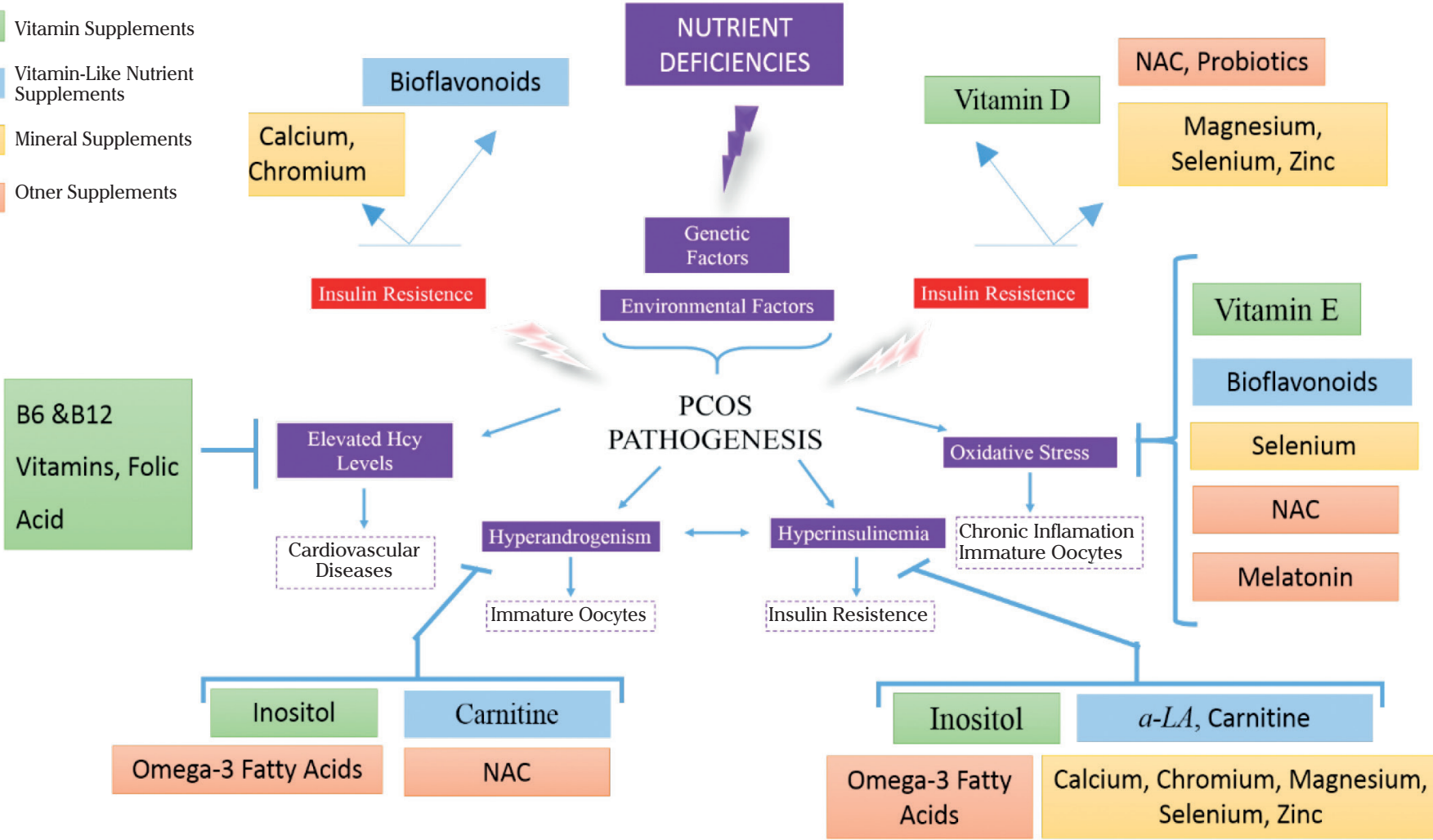

Figure 1. The effects of vitamins, minerals, vitamin-like substances and other supplements on the pathophysiology of PCOS NAC: N-acetyl-L-cysteine; $\alpha$-LA: $\alpha$-linolenic acid; PCOS: Polycystic ovary syndrome 
groups; vitamins, minerals, vitamin-like substances, and other nutrients and each substance was evaluated in terms of treated dose, duration, and effectiveness in terms of their ability to prevent PCOS complications. In addition, we summarized how supplementation of different vitamins, minerals, and other supplements contribute to prevent complications of PCOS (Figure 1).

Figure 1 indicates that interactions between genetic factors and some nutrient deficiencies cause PCOS pathophysiologyrelated symptoms such as elevated Hcy levels, oxidative stress, hyperandrogenism, and hyperinsulinemia. In particular, deficiencies of vitamin D, bioflavonoids, Ca, chromium, NAC, probiotics, magnesium, zinc, and selenium are associated with IR. Therefore, the treatment of women with PCOS with these supplements provides improvement for hyperinsulinemia and increased insulin sensitivity. Inositol, vitamin A, carnitine, omega-3 fatty acids, and NAC supplements affect hyperandrogenism. Inositol and omega 3 supplementation in particular help the recovery of PCOS with regard to metabolic and reproductive parameters. Apart from that, vitamin B6, B12, and folic acid have beneficial effects in abnormal Hcy levels and also vitamin $\mathrm{E}, \alpha$-linolenic acid, bioflavonoids, selenium, NAC, and MT supplements help to remove the oxidative stress of PCOS. Nevertheless, the safe use and effectiveness of herbal medicine and nutrient supplements, except for inositol and omega-3 fatty acid, have not been clearly demonstrated and more studies are needed in these areas (147).

\section{Study Limitations}

A limitation of our study was the huge number of related articles published: the doses, types, and combinations of supplemented nutrients are extremely different from each other, which depends on the investigated group, thus it makes the evaluation of the results difficult. Another limitation is the dose of nutrients used in the studies, as well as the insufficient diagnostic criteria used for PCOS. In addition, each woman with PCOS requires different supplementation depending on the signs and physiologic abnormalities. For instance, some patients have infertility due to PCOS, whereas others have endocrine and metabolic dysfunctions. However, most nutrient supplementation research focuses on the metabolic aspects of PCOS. Therefore, this review mostly focused on the therapeutic effects on the metabolic and endocrine dysfunctions instead of infertility, which is also a limiting factor in this study. Large, molecular scale up studies can be planned to illuminate the disrupted signaling pathways in PCOS. In this way, nutrients can be used effectively in the management of all aspects of PCOS via a molecular targeting strategy.

In conclusion, vitamin or mineral supplements can exert beneficial effects on PCOS-related symptoms such as immature oocytes, hyperinsulinemia, hyperandrogenism, increased
BMI, cardiovascular disorders, and mental and psychological problems.

Peer-review: Externally peer-reviewed.

Author Contributions: Concept - E.G., A.Y.; Design - E.G., A.Y.; Supervision - A.Y., B.Y.; Materials - E.G., A.Y., B.Y.; Data Collection and/or Processing - E.G.; Analysis and/or Interpretation - E.G.; Literature Review - E.G.; Writer - E.G.; Critical Review - A.Y., B.Y.

Conflict of Interest: No conflict of interest was declared by the authors.

Financial Disclosure: The authors declared that this study has received no financial support.

\section{References}

1. Knochenhauer ES, Key TJ, Kahsar-Miller M, Waggoner W, Boots LR, Azziz R. Prevalence of the polycystic ovary syndrome in unselected black and white women of the southeastern United States: a prospective study. J Clin Endocrinol Metab 1998; 83: 3078-82.

2. Carreau AM, Baillargeon JP. PCOS in adolescence and type 2 diabetes. Curr Diab Rep 2015; 15: 564.

3. Stein JD, Andrews C, Musch DC, Green C, Lee PP. Sight-Threatening Ocular Diseases Remain Underdiagnosed Among Children Of Less Affluent Families. Health Aff (Millwood) 2016; 35: 1359-66.

4. Rotterdam ESHRE/ASRM-Sponsored PCOS consensus workshop group. Revised 2003 consensus on diagnostic criteria and longterm health risks related to polycystic ovary syndrome (PCOS). Hum Reprod 2004; 19: 41-7.

5. Azziz R, Carmina E, Dewailly D, Diamanti-Kandarakis E, EscobarMorreale HF, Futterweit W, et al. The Androgen Excess and PCOS Society criteria for the polycystic ovary syndrome: the complete task force report. Fertil Steril 2009; 91: 456-88.

6. Sheehan MT. Polycystic ovarian syndrome: diagnosis and management. Clin Med Res 2004; 2: 13-27.

7. Sirmans SM, Pate KA. Epidemiology, diagnosis, and management of polycystic ovary syndrome. Clin Epidemiol 2013; 6: 1-13.

8. Carmina E. Genetic and environmental aspect of polycystic ovary syndrome. J Endocrinol Invest 2003; 26: 1151-9.

9. Doi SA. Neuroendocrine dysfunction in PCOS: a critique of recent reviews. Clin Med Res 2008; 6: 47-53.

10. Takayama K, Fukaya T, Sasano H, Funayama Y, Suzuki T, Takaya $\mathrm{R}$, et al. Immunohistochemical study of steroidogenesis and cell proliferation in polycystic ovarian syndrome. Hum Reprod 1996; 11: $1387-92$

11. Yaba A, Demir N. The mechanism of mTOR (mammalian target of rapamycin) in a mouse model of polycystic ovary syndrome (PCOS). J Ovarian Res 2012; 5: 38.

12. Diamanti-Kandarakis E, Dunaif A. Insulin resistance and the polycystic ovary syndrome revisited: an update on mechanisms and implications. Endocr Rev 2012; 33: 981-1030.

13. Ehrmann DA. Polycystic ovary syndrome. N Engl J Med 2005; 352: 1223-36.

14. Kahn CR. Banting Lecture. Insulin action, diabetogenes, and the cause of type II diabetes. Diabetes 1994; 43: 1066-84. 
15. Yu J, Yaba A, Kasiman C, Thomson T, Johnson J. mTOR controls ovarian follicle growth by regulating granulosa cell proliferation. PLoS One 2011; 6: 21415

16. Muscogiuri G, Policola C, Prioletta A, Sorice G, Mezza T, Lassandro A, et al. Low levels of 25(OH)D and insulin-resistance: 2 unrelated features or a cause-effect in PCOS? Clin Nutr 2012; 31: 476-80.

17. Thomson RL, Spedding S, Buckley JD. Vitamin D in the aetiology and management of polycystic ovary syndrome. Clin Endocrinol (Oxf) 2012; 77: 343-50.

18. Jakimiuk AJ, Szamatowicz J. (The role of inositol deficiency in the etiology of polycystic ovary syndrome disorders). Ginekol Pol 2014; 85: 54-7.

19. Pu Y, Wang Z, Bian Y, Zhang F, Yang P, Li Y, et al. All-trans retinoic acid improves goat oocyte nuclear maturation and reduces apoptotic cumulus cells during in vitro maturation. Anim Sci J 2014; 85: 833-9.

20. Deb GK, Dey SR, Bang JI, Lee JG, Kong IK. 9-cis Retinoic acid inhibits cumulus cell apoptosis during the maturation of bovine cumulus-oocyte-complexes. J Anim Sci 2012; 90: 1798-806.

21. Wood JR, Nelson VL, Ho C, Jansen E, Wang CY, Urbanek M, et al. The molecular phenotype of polycystic ovary syndrome (PCOS) theca cells and new candidate PCOS genes defined by microarray analysis. J Biol Chem 2003; 278: 26380-90.

22. Wickenheisser JK, Nelson-DeGrave VL, Hendricks KL, Legro RS, Strauss JF, 3rd, McAllister JM. Retinoids and retinol differentially regulate steroid biosynthesis in ovarian theca cells isolated from normal cycling women and women with polycystic ovary syndrome. J Clin Endocrinol Metab 2005; 90: 4858-65.

23. Hahn S, Backhaus M, Broecker-Preuss M, Tan S, Dietz T, Kimmig $\mathrm{R}$, et al. Retinol-binding protein 4 levels are elevated in polycystic ovary syndrome women with obesity and impaired glucose metabolism. Eur J Endocrinol 2007; 157: 201-7.

24. Tan BK, Chen J, Lehnert H, Kennedy R, Randeva HS. Raised serum, adipocyte, and adipose tissue retinol-binding protein 4 in overweight women with polycystic ovary syndrome: effects of gonadal and adrenal steroids. J Clin Endocrinol Metab 2007; 92: 2764-72.

25. Yarali H, Yildirir A, Aybar F, Kabakci G, Bükülmez O, Akgül E, et al. Diastolic dysfunction and increased serum homocysteine concentrations may contribute to increased cardiovascular risk in patients with polycystic ovary syndrome. Fertil Steril 2001; 76: 511-6.

26. de la Calle M, Usandizaga R, Sancha M, Magdaleno F, Herranz A, Cabrillo E. Homocysteine, folic acid and B-group vitamins in obstetrics and gynaecology. Eur J Obstet Gynecol Reprod Biol 2003; 107: 125-34.

27. Loverro G, Lorusso F, Mei L, Depalo R, Cormio G, Selvaggi L. The plasma homocysteine levels are increased in polycystic ovary syndrome. Gynecol Obstet Invest 2002; 53: 157-62.

28. Badawy A, State O, El Gawad S, El Aziz OA. Plasma homocysteine and polycystic ovary syndrome: the missed link. Eur J Obstet Gynecol Reprod Biol 2007; 131: 68-72.

29. Kaya C, Cengiz SD, Satiroglu H. Obesity and insulin resistance associated with lower plasma vitamin B12 in PCOS. Reprod Biomed Online 2009; 19: 721-6.

30. Kazerooni T, Asadi N, Dehbashi S, Zolghadri J. Effect of folic acid in women with and without insulin resistance who have hyperhomocysteinemic polycystic ovary syndrome. Int J Gynaecol Obstet 2008; 101: 156-60.

31. Randeva HS, Lewandowski KC, Drzewoski J, Brooke-Wavell K, O'Callaghan C, Czupryniak L, et al. Exercise decreases plasma total homocysteine in overweight young women with polycystic ovary syndrome. J Clin Endocrinol Metab 2002; 87: 4496-501.
32. de Jager J, Kooy A, Lehert P, Wulffele MG, van der Kolk J, Bets D, et al. Long term treatment with metformin in patients with type 2 diabetes and risk of vitamin B-12 deficiency: randomised placebo controlled trial. BMJ 2010; 340: 2181.

33. Kilicdag EB, Bagis T, Zeyneloglu HB, Tarim E, Aslan E, Haydardedeoglu B, et al. Homocysteine levels in women with polycystic ovary syndrome treated with metformin versus rosiglitazone: a randomized study. Hum Reprod 2005; 20: 894-9.

34. Kilicdag EB, Bagis T, Tarim E, Aslan E, Erkanli S, Simsek E, et al. Administration of B-group vitamins reduces circulating homocysteine in polycystic ovarian syndrome patients treated with metformin: a randomized trial. Hum Reprod 2005; 20: 1521-8.

35. Palomba S, Falbo A, Giallauria F, Russo T, Tolino A, Zullo F, et al. Effects of metformin with or without supplementation with folate on homocysteine levels and vascular endothelium of women with polycystic ovary syndrome. Diabetes Care 2010; 33: 246-51.

36. Daughaday WH, Larner J, Hartnett C. The synthesis of inositol in the immature rat and chick embryo. J Biol Chem 1955; 212: 86975.

37. Papaleo E, Unfer V, Baillargeon JP, Chiu TT. Contribution of myoinositol to reproduction. Eur J Obstet Gynecol Reprod Biol 2009; 147: 120-3.

38. Unfer V, Carlomagno G, Dante G, Facchinetti F. Effects of myoinositol in women with PCOS: a systematic review of randomized controlled trials. Gynecol Endocrinol 2012; 28: 509-15.

39. Carlomagno G, De Grazia S, Unfer V, Manna F. Myo-inositol in a new pharmaceutical form: a step forward to a broader clinical use. Expert Opin Drug Deliv 2012; 9: 267-71.

40. Dinicola S, Chiu TT, Unfer V, Carlomagno G, Bizzarri M. The rationale of the myo-inositol and D-chiro-inositol combined treatment for polycystic ovary syndrome. J Clin Pharmacol 2014; 54: 1079-92.

41. Carlomagno G, Unfer V, Roseff S. The D-chiro-inositol paradox in the ovary. Fertil Steril 2011; 95: 2515-6.

42. Nestler JE, Unfer V. Reflections on inositol(s) for PCOS therapy: steps toward success. Gynecol Endocrinol 2015; 31: 501-5.

43. Nestler JE, Jakubowicz DJ, Reamer P, Gunn RD, Allan G. Ovulatory and metabolic effects of D-chiro-inositol in the polycystic ovary syndrome. N Engl J Med 1999; 340: 1314-20.

44. Baillargeon JP, Iuorno MJ, Jakubowicz DJ, Apridonidze T, He N, Nestler JE. Metformin therapy increases insulin-stimulated release of D-chiro-inositol-containing inositolphosphoglycan mediator in women with polycystic ovary syndrome. J Clin Endocrinol Metab 2004; 89: 242-9

45. Gerli S, Papaleo E, Ferrari A, Di Renzo GC. Randomized, double blind placebo-controlled trial: effects of myo-inositol on ovarian function and metabolic factors in women with PCOS. Eur Rev Med Pharmacol Sci 2007; 11: 347-54.

46. Papaleo E, Unfer V, Baillargeon JP, De Santis L, Fusi F, Brigante C, et al. Myo-inositol in patients with polycystic ovary syndrome: a novel method for ovulation induction. Gynecol Endocrinol 2007; 23: 700-3.

47. Genazzani AD, Lanzoni C, Ricchieri F, Jasonni VM. Myo-inositol administration positively affects hyperinsulinemia and hormonal parameters in overweight patients with polycystic ovary syndrome. Gynecol Endocrinol 2008; 24: 139-44.

48. Costantino D, Minozzi G, Minozzi E, Guaraldi C. Metabolic and hormonal effects of myo-inositol in women with polycystic ovary syndrome: a double-blind trial. Eur Rev Med Pharmacol Sci 2009; 13: 105-10.

49. Minozzi M, Costantino D, Guaraldi C, Unfer V. The effect of a combination therapy with myo-inositol and a combined oral contraceptive pill versus a combined oral contraceptive pill alone 
on metabolic, endocrine, and clinical parameters in polycystic ovary syndrome. Gynecol Endocrinol 2011; 27: 920-4.

50. Morgante G, Orvieto R, Di Sabatino A, Musacchio MC, De Leo V. The role of inositol supplementation in patients with polycystic ovary syndrome, with insulin resistance, undergoing the low-dose gonadotropin ovulation induction regimen. Fertil Steril 2011; 95: 2642-4.

51. Alvarez JA, Ashraf A. Role of vitamin d in insulin secretion and insulin sensitivity for glucose homeostasis. Int J Endocrinol 2010; 2010: 351385 .

52. Krul-Poel YH, Snackey C, Louwers Y, Lips P, Lambalk CB, Laven JS, et al. The role of vitamin $\mathrm{D}$ in metabolic disturbances in polycystic ovary syndrome: a systematic review. Eur J Endocrinol 2013; 169: 853-65.

53. Yildizhan R, Kurdoglu M, Adali E, Kolusari A, Yildizhan B, Sahin $\mathrm{HG}$, et al. Serum 25-hydroxyvitamin D concentrations in obese and non-obese women with polycystic ovary syndrome. Arch Gynecol Obstet 2009; 280: 559-63.

54. Joham AE, Teede HJ, Cassar S, Stepto NK, Strauss BJ, Harrison $\mathrm{CL}$, et al. Vitamin D in polycystic ovary syndrome: Relationship to obesity and insulin resistance. Mol Nutr Food Res 2016; 60: 110-8.

55. Selimoglu H, Duran C, Kiyici S, Ersoy C, Guclu M, Ozkaya G, et al. The effect of vitamin $D$ replacement therapy on insulin resistance and androgen levels in women with polycystic ovary syndrome. J Endocrinol Invest 2010; 33: 234-8.

56. Kotsa K, Yavropoulou MP, Anastasiou O, Yovos JG. Role of vitamin $\mathrm{D}$ treatment in glucose metabolism in polycystic ovary syndrome. Fertil Steril 2009; 92: 1053-8.

57. Irani M, Minkoff H, Seifer DB, Merhi Z. Vitamin D increases serum levels of the soluble receptor for advanced glycation end products in women with PCOS. J Clin Endocrinol Metab 2014; 99: 886-90.

58. Jafari-Sfidvajani S, Ahangari R, Hozoori M, Mozaffari-Khosravi $\mathrm{H}$, Fallahzadeh $\mathrm{H}$, Nadjarzadeh A. The effect of vitamin D supplementation in combination with low-calorie diet on anthropometric indices and androgen hormones in women with polycystic ovary syndrome: a double-blind, randomized, placebocontrolled trial. J Endocrinol Invest 2018; 41: 597-607.

59. Palamanda JR, Kehrer JP. Involvement of vitamin E and protein thiols in the inhibition of microsomal lipid peroxidation by glutathione. Lipids 1993; 28: 427-31.

60. Cicek N, Eryilmaz OG, Sarikaya E, Gulerman C, Genc Y. Vitamin E effect on controlled ovarian stimulation of unexplained infertile women. J Assist Reprod Genet 2012; 29: 325-8.

61. Izadi A, Ebrahimi S, Shirzai S, Taghizadeh S, Parized M, Farzadi $\mathrm{L}$, et al. Hormonal and metabolic effects of coenzyme q10 and/ or vitamin $\mathrm{E}$ in patients with polycystic ovary syndrome. J Clin Endocrinol Metab 2018

62. Ebrahimi FA, Samimi M, Foroozanfard F, Jamilian M, Akbari H, Rahmani E, et al. The Effects of Omega-3 Fatty Acids and Vitamin E Co-Supplementation on Indices of Insulin Resistance and Hormonal Parameters in Patients with Polycystic Ovary Syndrome: A Randomized, Double-Blind, Placebo-Controlled Trial. Exp Clin Endocrinol Diabetes 2017; 125: 353-9.

63. Biewenga GP, Haenen GR, Bast A. The pharmacology of the antioxidant lipoic acid. Gen Pharmacol 1997; 29: 315-31.

64. Lee WJ, Koh EH, Won JC, Kim MS, Park JY, Lee KU. Obesity: the role of hypothalamic AMP-activated protein kinase in body weight regulation. Int J Biochem Cell Biol 2005; 37: 2254-9.

65. Masharani U, Gjerde C, Evans JL, Youngren JF, Goldfine ID. Effects of controlled-release alpha lipoic acid in lean, nondiabetic patients with polycystic ovary syndrome. J Diabetes Sci Technol 2010; 4: 359-64.

66. Cianci A, Panella M, Fichera M, Falduzzi C, Bartolo M, Caruso S. d-chiro-Inositol and alpha lipoic acid treatment of metabolic and menses disorders in women with PCOS. Gynecol Endocrinol 2015; 31: 483-6.

67. Ross JA, Kasum CM. Dietary flavonoids: bioavailability, metabolic effects, and safety. Annu Rev Nutr 2002; 22: 19-34.

68. Oh JS, Kim H, Vijayakumar A, Kwon O, Choi YJ, Huh KB, et al. Association between dietary flavanones intake and lipid profiles according to the presence of metabolic syndrome in Korean women with type 2 diabetes mellitus. Nutr Res Pract 2016; 10: 67-73.

69. Romualdi D, Costantini B, Campagna G, Lanzone A, Guido M. Is there a role for soy isoflavones in the therapeutic approach to polycystic ovary syndrome? Results from a pilot study. Fertil Steril 2008; 90: 1826-33.

70. Shah KN, Patel SS. Phosphatidylinositide 3-kinase inhibition: A new potential target for the treatment of polycystic ovarian syndrome. Pharm Biol 2016; 54: 975-83.

71. Steiber A, Kerner J, Hoppel CL. Carnitine: a nutritional, biosynthetic, and functional perspective. Mol Aspects Med 2004; 25: 455-73.

72. Fenkci SM, Fenkci V, Oztekin O, Rota S, Karagenc N. Serum total L-carnitine levels in non-obese women with polycystic ovary syndrome. Hum Reprod 2008; 23: 1602-6.

73. Vigerust NF, Bohov P, Bjorndal B, Seifert R, Nygard O, Svardal A, et al. Free carnitine and acylcarnitines in obese patients with polycystic ovary syndrome and effects of pioglitazone treatment. Fertil Steril 2012; 98: 1620-6.

74. Dunning KR, Robker RL. Promoting lipid utilization with l-carnitine to improve oocyte quality. Anim Reprod Sci 2012; 134: 69-75.

75. Dumesic DA, Abbott DH. Implications of polycystic ovary syndrome on oocyte development. Semin Reprod Med 2008; 26: 53-61.

76. Ismail AM, Hamed AH, Saso S, Thabet HH. Adding L-carnitine to clomiphene resistant PCOS women improves the quality of ovulation and the pregnancy rate. A randomized clinical trial. Eur J Obstet Gynecol Reprod Biol 2014; 180: 148-52.

77. Jamilian H, Jamilian M, Samimi M, Afshar Ebrahimi F, Rahimi $\mathrm{M}$, Bahmani $\mathrm{F}$, et al. Oral carnitine supplementation influences mental health parameters and biomarkers of oxidative stress in women with polycystic ovary syndrome: a randomized, doubleblind, placebo-controlled trial. Gynecol Endocrinol 2017; 33: 442-7.

78. Homa ST, Carroll J, Swann K. The role of calcium in mammalian oocyte maturation and egg activation. Hum Reprod 1993; 8: 1274 81.

79. Ullah G, Jung P, Machaca K. Modeling Ca2 + signaling differentiation during oocyte maturation. Cell Calcium 2007; 42: 556-64.

80. De Felici M, Dolci S, Siracusa G. An Increase of Intracellular Free $\mathrm{Ca} 2+$ Is Essential for Spontaneous Meiotic Resumption by Mouse Oocytes. J Exp Zool 1991; 260: 401-5.

81. Gedik O, Zileli MS. Effects of hypocalcemia and theophylline on glucose tolerance and insulin release in human beings. Diabetes 1977; 26: 813-9.

82. Mazloomi S, Sharifi F, Hajihosseini R, Kalantari S, Mazloomzadeh S. Association between Hypoadiponectinemia and Low Serum Concentrations of Calcium and Vitamin D in Women with Polycystic Ovary Syndrome. ISRN Endocrinol 2012; 2012: 949427.

83. Ranjzad F, Mahban A, Shemirani AI, Mahmoudi T, Vahedi M, Nikzamir A, et al. Influence of gene variants related to calcium homeostasis on biochemical parameters of women with polycystic ovary syndrome. J Assist Reprod Genet 2011; 28: 225-32.

84. Firouzabadi Rd, Aflatoonian A, Modarresi S, Sekhavat L, MohammadTaheri S. Therapeutic effects of calcium \& vitamin D supplementation in women with PCOS. Complement Ther Clin Pract 2012; 18: 85-8.

85. Anderson RA. Chromium in the prevention and control of diabetes. Diabetes Metab 2000; 26: 22-7. 
86. Chakraborty P, Ghosh S, Goswami SK, Kabir SN, Chakravarty B, Jana K. Altered Trace Mineral Milieu Might Play An Aetiological Role in the Pathogenesis of Polycystic Ovary Syndrome. Biol Trace Elem Res 2013; 152: 9-15

87. Lucidi RS, Thyer AC, Easton CA, Holden AE, Schenken RS, Brzyski RG. Effect of chromium supplementation on insulin resistance and ovarian and menstrual cyclicity in women with polycystic ovary syndrome. Fertil Steril 2005; 84: 1755-7.

88. Jamilian M, Asemi Z. Chromium Supplementation and the Effects on Metabolic Status in Women with Polycystic Ovary Syndrome: A Randomized, Double-Blind, Placebo-Controlled Trial. Ann Nutr Metab 2015; 67: 42-8.

89. Amooee S, Parsanezhad ME, Ravanbod Shirazi M, Alborzi S, Samsami A. Metformin versus chromium picolinate in clomiphene citrate-resistant patients with PCOs: A double-blind randomized clinical trial. Iran J Reprod Med 2013; 11: 611-8.

90. Amr N, Abdel-Rahim HE. The effect of chromium supplementation on polycystic ovary syndrome in adolescents. J Pediatr Adolesc Gynecol 2015; 28: 114-8.

91. Touyz RM. Magnesium in clinical medicine. Front Biosci 2004; 9: 1278-93.

92. Saris NE, Mervaala E, Karppanen H, Khawaja JA, Lewenstam A. Magnesium. An update on physiological, clinical and analytical aspects. Clin Chim Acta 2000; 294: 1-26.

93. Bresink I, Danysz W, Parsons CG, Mutschler E. Different Binding Affinities of Nmda Receptor-Channel Blockers in Various Brain-Regions - Indication of Nmda Receptor Heterogeneity. Neuropharmacology 1995; 34: 533-40.

94. Iseri LT, French JH. Magnesium: nature's physiologic calcium blocker. Am Heart J 1984; 108: 188-93.

95. Eby GA, Eby KL. Rapid recovery from major depression using magnesium treatment. Med Hypotheses 2006; 67: 362-70.

96. Song Y, Manson JE, Cook NR, Albert CM, Buring JE, Liu S. Dietary magnesium intake and risk of cardiovascular disease among women. Am J Cardiol 2005; 96: 1135-41.

97. Young LT, Robb JC, Levitt AJ, Cooke RG, Joffe RT. Serum $\mathrm{Mg} 2+$ and $\mathrm{Ca} 2+/ \mathrm{Mg} 2+$ ratio in major depressive disorder. Neuropsychobiology 1996; 34: 26-8.

98. Mirone M, Giannetta E, Isidori AM. Selenium and reproductive function. A systematic review. J Endocrinol Invest 2013; 36: 28-36.

99. Coskun A, Arikan T, Kilinc M, Arikan DC, Ekerbicer HC. Plasma selenium levels in Turkish women with polycystic ovary syndrome. Eur J Obstet Gynecold Reprod Biol 2013; 168: 183-6.

100. Rezvanfar MA, Rezvanfar MA, Ahmadi A, Shojaei-Saadi HA, Baeeri M, Abdollahi M. Molecular mechanisms of a novel seleniumbased complementary medicine which confers protection against hyperandrogenism-induced polycystic ovary. Theriogenology 2012; 78: 620-31.

101. Stapleton SR. Selenium: an insulin-mimetic. Cell Mol Life Sci 2000; 57: 1874-9.

102. Zadeh Modarres S, Heidar Z, Foroozanfard F, Rahmati Z, Aghadavod E, Asemi Z. The Effects of Selenium Supplementation on Gene Expression Related to Insulin and Lipid in Infertile Polycystic Ovary Syndrome Women Candidate for In Vitro Fertilization: a Randomized, Double-Blind, Placebo-Controlled Trial. Biol Trace Elem Res 2018; 183: 218-25.

103. Jamilian M, Razavi M, Fakhrie Kashan Z, Ghandi Y, Bagherian T, Asemi Z. Metabolic response to selenium supplementation in women with polycystic ovary syndrome: a randomized, doubleblind, placebo-controlled trial. Clin Endocrinol 2015; 82: 885-91.

104. Tubek S. Zinc supplementation or regulation of its homeostasis: advantages and threats. Biol Trace Elem Res 2007; 119: 1-9.
105. Chausmer AB. Zinc, insulin and diabetes. J Am Coll Nutr 1998; 17: 109-15.

106. Di Martino G, Matera MG, De Martino B, Vacca C, Di Martino S, Rossi F. Relationship between Zinc and Obesity. J Med 1993; 24: 177-83.

107. Bolkent S, Yanardag R, Bolkent S, Mutlu O, Yildirim S, Kangawa $\mathrm{K}$, et al. The effect of zinc supplementation on ghrelinimmunoreactive cells and lipid parameters in gastrointestinal tissue of streptozotocin-induced female diabetic rats. Mol Cell Biochem 2006; 286: 77-85.

108. Guler I, Himmetoglu O, Turp A, Erdem A, Erdem M, Onan MA, et al. Zinc and Homocysteine Levels in Polycystic Ovarian Syndrome Patients with Insulin Resistance. Biol Trace Elem Res 2014; 158: 297-304.

109. Ciaraldi TP, el-Roeiy A, Madar Z, Reichart D, Olefsky JM, Yen SS. Cellular mechanisms of insulin resistance in polycystic ovarian syndrome. J Clin Endocrinol Metab 1992; 75: 577-83.

110. Dunaif A. Insulin resistance and the polycystic ovary syndrome: mechanism and implications for pathogenesis. Endocr Rev 1997; 18: 774-800.

111. Beletate V, El Dib RP, Atallah AN. Zinc supplementation for the prevention of type 2 diabetes mellitus. Cochrane Database Syst Rev 2007: CD005525.

112. Legro RS, Kunselman AR, Dunaif A. Prevalence and predictors of dyslipidemia in women with polycystic ovary syndrome. Am J Med 2001; 111: 607-13.

113. Ahmed Z, Tabrizi S, Li A, Houlden H, Sailer A, Lees AJ, et al. A case of Huntington's disease phenocopy characterised by pallidonigro-luysian degeneration with brain-iron accumulation and p62positive glial inclusions. Eur J Neurol 2010; 17: 379.

114. Adriaens I, Jacquet P, Cortvrindt R, Janssen K, Smitz J. Melatonin has dose-dependent effects on folliculogenesis, oocyte maturation capacity and steroidogenesis. Toxicology 2006; 228: 333-43.

115. Tamura H, Nakamura Y, Korkmaz A, Manchester LC, Tan DX, Sugino N, et al. Melatonin and the ovary: physiological and pathophysiological implications. Fertil Steril 2009; 92: 328-43.

116. Carlomagno G, Nordio M, Chiu TT, Unfer V. Contribution of myoinositol and melatonin to human reproduction. Eur J Obstet Gynecol Reprod Biol 2011; 159: 267-72.

117. Wei D, Zhang C, Xie J, Song X, Yin B, Liu Q, et al. Supplementation with low concentrations of melatonin improves nuclear maturation of human oocytes in vitro. J Assist Reprod Genet 2013; 30: 933-8.

118. Tamura H, Nakamura Y, Terron MP, Flores LJ, Manchester LC, Tan DX, et al. Melatonin and pregnancy in the human. Reprod Toxicol 2008; 25: 291-303.

119. Kim MK, Park EA, Kim HJ, Choi WY, Cho JH, Lee WS, et al. Does supplementation of in-vitro culture medium with melatonin improve IVF outcome in PCOS? Reprod Biomed Online 2013; 26 : $22-9$.

120. Dickinson DA, Moellering DR, Iles KE, Patel RP, Levonen AL, Wigley A, et al. Cytoprotection against oxidative stress and the regulation of glutathione synthesis. Biol Chem 2003; 384: 527-37.

121. Liu J, Liu M, Ye X, Liu K, Huang J, Wang L, et al. Delay in oocyte aging in mice by the antioxidant $\mathrm{N}$-acetyl-L-cysteine (NAC). Hum Reprod 2012; 27: 1411-20.

122. Santini MT, Cametti C, Indovina PL, Peterson SW. Membrane electrical properties associated with insulin receptor downregulation in human erythrocytes. Exp Hematol 1994; 22 : 40-4.

123. Fulghesu AM, Ciampelli M, Muzj G, Belosi C, Selvaggi L, Ayala $\mathrm{GF}$, et al. N-acetyl-cysteine treatment improves insulin sensitivity 
in women with polycystic ovary syndrome. Fertil Steril 2002; 77: 1128-35.

124. Elnashar A, Fahmy M, Mansour A, Ibrahim K. N-acetyl cysteine vs. metformin in treatment of clomiphene citrate-resistant polycystic ovary syndrome: a prospective randomized controlled study. Fertil Steril 2007; 88: 406-9.

125. Oner G, Muderris, II. Clinical, endocrine and metabolic effects of metformin vs $\mathrm{N}$-acetyl-cysteine in women with polycystic ovary syndrome. Eur J Obstet Gynecol Reprod Biol 2011; 159: 127-31.

126. Vargas ML, Almario RU, Buchan W, Kim K, Karakas SE. Metabolic and endocrine effects of long-chain versus essential omega-3 polyunsaturated fatty acids in polycystic ovary syndrome. Metabolism 2011; 60: 1711-8.

127. Calder PC. n-3 polyunsaturated fatty acids, inflammation, and inflammatory diseases. Am J Clin Nutr 2006; 83(6 Suppl): 1505-19.

128. Poudyal H, Panchal SK, Diwan V, Brown L. Omega-3 fatty acids and metabolic syndrome: effects and emerging mechanisms of action. Prog Lipid Res 2011; 50: 372-87.

129. Shahnazi V, Zaree M, Nouri M, Mehrzad-Sadaghiani M, Fayezi S, Darabi M, et al. Influence of omega-3 fatty acid eicosapentaenoic acid on IGF-1 and COX-2 gene expression in granulosa cells of PCOS women. Iran J Reprod Med 2015; 13: 71-8.

130. Akinkuolie AO, Ngwa JS, Meigs JB, Djousse L. Omega-3 polyunsaturated fatty acid and insulin sensitivity: a meta-analysis of randomized controlled trials. Clin Nutr 2011; 30: 702-7.

131. Kasim-Karakas SE, Almario RU, Gregory L, Wong R, Todd H, Lasley BL. Metabolic and endocrine effects of a polyunsaturated fatty acid-rich diet in polycystic ovary syndrome. J Clin Endocrinol Metab 2004; 89: 615-20.

132. Phelan N, O'Connor A, Kyaw Tun T, Correia N, Boran G, Roche HM, et al. Hormonal and metabolic effects of polyunsaturated fatty acids in young women with polycystic ovary syndrome: results from a cross-sectional analysis and a randomized, placebocontrolled, crossover trial. Am J Clin Nutr 2011; 93: 652-62.

133. Kalgaonkar S, Almario RU, Gurusinghe D, Garamendi EM, Buchan W, Kim K, et al. Differential effects of walnuts vs almonds on improving metabolic and endocrine parameters in PCOS. Eur J Clin Nutr 2011; 65: 386-93.

134. Mohammadi E, Rafraf M. Benefits of omega-3 Fatty acids supplementation on serum paraoxonase 1 activity and lipids ratios in polycystic ovary syndrome. Health Promot Perspect 2012; 2: $197-204$
135. Rafraf M, Mohammadi E, Asghari-Jafarabadi M, Farzadi L. Omega-3 Fatty Acids Improve Glucose Metabolism without Effects on Obesity Values and Serum Visfatin Levels in Women with Polycystic Ovary Syndrome. J Am Coll Nutr 2012; 31: 361-8.

136. Oner G, Muderris II. Efficacy of omega-3 in the treatment of polycystic ovary syndrome. J Obstet Gynaecol 2013; 33: 289-91.

137. Roberfroid MB. Prebiotics and probiotics: are they functional foods? Am J Clin Nutr 2000; 71 (6 Suppl): 1682-7.

138. Fuller R. Probiotics in Human Medicine. Gut 1991; 32: 439-42.

139. Allen SJ, Jordan S, Storey M, Thornton CA, Gravenor M, Garaiova I, et al. Dietary supplementation with lactobacilli and bifidobacteria is well tolerated and not associated with adverse events during late pregnancy and early infancy. J Nutr 2010; 140: 483-8.

140. Ejtahed HS, Mohtadi-Nia J, Homayouni-Rad A, Niafar M, AsghariJafarabadi M, Mofid V. Probiotic yogurt improves antioxidant status in type 2 diabetic patients. Nutrition 2012; 28: 539-43.

141. Yadav H, Jain S, Sinha PR. Antidiabetic effect of probiotic dahi containing Lactobacillus acidophilus and Lactobacillus casei in high fructose fed rats. Nutrition 2007; 23: 62-8.

142. Shoaei T, Heidari-Beni M, Tehrani HG, Feizi A, Esmaillzadeh A, Askari G. Effects of Probiotic Supplementation on Pancreatic betacell Function and C-reactive Protein in Women with Polycystic Ovary Syndrome: A Randomized Double-blind Placebo-controlled Clinical Trial. Int J Prev Med 2015; 6: 27.

143. Goodarzi MO, Dumesic DA, Chazenbalk G, Azziz R. Polycystic ovary syndrome: etiology, pathogenesis and diagnosis. Nat Rev Endocrinol 2011; 7: 219-31.

144. Ahmadi S, Jamilian M, Karamali M, Tajabadi-Ebrahimi M, Jafari P, Taghizadeh M, et al. Probiotic supplementation and the effects on weight loss, glycaemia and lipid profiles in women with polycystic ovary syndrome: a randomized, double-blind, placebo-controlled trial. Hum Fertil (Camb) 2017; 20: 254-61.

145. Tremellen K, Pearce K. Dysbiosis of Gut Microbiota (DOGMA) - A novel theory for the development of Polycystic Ovarian Syndrome. Med Hypotheses 2012; 79: 104-12.

146. Guo Y, Qi Y, Yang X, Zhao L, Wen S, Liu Y, et al. Association between polycystic ovary syndrome and gut microbiota. Plos one 2016; 11: e0153196.

147. Arentz S, Smith CA, Abbott J, Bensoussan A. Nutritional supplements and herbal medicines for women with polycystic ovary syndrome; a systematic review and meta-analysis. BMC Complement Altern Med 2017; 17: 500. 